\title{
ATENÇÃO PRIMÁRIA À SAÚDE E O PERFIL SOCIAL DO TRABALHADOR COMUNITÁRIO EM PERSPECTIVA HISTÓRICA
}

\author{
PRIMARY HEALTHCARE AND THE COMMUNITY SOCIAL WORKER PROFILE \\ IN HISTORICAL PERSPECTIVE
}

\author{
Angélica Ferreira Fonseca ${ }^{1}$ \\ Márcia Valéria Guimarães Cardoso Morosini ${ }^{2}$ \\ Maria Helena Magalhães Mendonça ${ }^{3}$
}

Resumo Em diversos países, e no Brasil em particular, a adoção do enfoque da atenção primária como reordenador de sistemas de saúde tem se consolidado dando destaque ao trabalhador comunitário, no Sistema Único de Saúde (SUS) denominado agente comunitário de saúde. Compreendendo que esse fato tem raízes antigas, este texto, com perspectiva histórica, se desenvolve com base em um exame de documentos e de bibliografia, orientando-se pelo mapeamento de projetos postos em disputa. Na análise, distinguiram-se tensões que perpassaram a configuração de propostas de atenção à saúde com as seguintes características: atuação contínua e vinculação ao território; educação em saúde como estratégia relevante; e conexão entre os serviços de saúde e as populações locais, mediada por um trabalhador que tem nessa função seu principal papel social. Analisam-se também características da constituição do trabalho do agente comunitário de saúde no SUS que representam desafios para a qualificação desses trabalhadores, tendo como parâmetro os direitos associados ao trabalho, a complexidade do trabalho em saúde e o seu papel técnico e político.

Palavras-chave atenção primária à saúde; trabalho em saúde; agente comunitário de saúde.
Abstract In several countries, and in Brazil in particular, the adoption of primary care as a factor to reorder health systems has been consolidated by highlighting the community worker, who is called a community health agent in the Sistema Único de Saúde (SUS, Unified Health System). Understanding that this fact has ancient roots, this paper, with a historical perspective, is developed based on a review of documents and literature, guided by the mapping of projects put into dispute. In the analysis, tensions that permeated the configuration of healthcare proposals with these characteristics were distinguished: continuous action and linkage to the territory; health education as a relevant strategy, and the connection between health services and local populations, mediated by a worker who has this role as his or her primary social role. Also analyzed were features that constitute the work of the community health worker in the SUS, which represent challenges to the qualifications of these workers, having the rights associated with the work, and the complexity of the healthcare work and its technical and political role as a parameter. Keywords primary healthcare; work in health; community health agent. 


\section{Introdução}

Em meados da década de 2000, são publicados dois documentos - um pela Organização Pan-Americana de Saúde (Opas) em 2005, e outro pela Organização Mundial de Saúde (OMS) em 2008, que, desde os respectivos títulos, elegem a atenção primária à saúde (APS) como enfoque privilegiado para a organização de sistemas de saúde.

No primeiro documento, intitulado Renovação da atenção primária em saúde nas Américas, a Opas apoia-se em debates com especialistas de vários países, inclusive do Brasil, e apresenta argumentos e indicações práticas para revigorar a política e as estratégias de implementação da APS nas Américas, configurando um texto de posicionamento político (Opas, 2005).

Já o documento de 2008, La atención primaria de salud: más necesaria que nunca, é um informe técnico da OMS sobre a saúde no mundo que contém, em dimensão ampliada, os argumentos políticos do texto de 2005. O texto suscita uma reflexão sobre as diferenças entre o contexto mundial em que se realizou a Conferência de Saúde em Alma-Ata (1978) e o atual e traz um discurso apoiado em dados científicos, sobretudo epidemiológicos, no qual são apresentadas evidências quanto aos benefícios de tomar a APS como enfoque (WHO, 2008).

Dessas publicações apreende-se, principalmente, o movimento de recuperação do debate em torno da APS, no qual são explicitadas as disputas entre os diferentes significados que a adoção desse enfoque como ponto principal de organização de sistemas de saúde pode assumir no contexto de cada país. Além disso, o debate recoloca perspectivas da relação entre Estado e sociedade diante do conjunto de questões que o campo da saúde faz emergir, tais como a responsabilização sobre a saúde coletiva, a relação entre os setores público e privado, os modos de financiamento das ações de saúde e a própria percepção da saúde como direito (Giovanella, 2008).

Autores como Ribeiro (2007) assinalam que a noção de APS apresenta algumas indefinições. Em nossa compreensão, tais indefinições não derivam de uma suposta insuficiência conceitual, mas do fato de a APS ser um campo de disputas em que se enfrentam diferentes orientações políticas, econômicas e sociais traduzidas em diversos modos de conceber o processo saúde-doença, os direitos sociais e o papel do Estado na produção e manutenção dos serviços públicos.

A configuração da APS é resultante da correlação de forças que se põem em disputa, e representa interesses distintos na conformação das políticas públicas e em seu ulterior desenvolvimento, devendo, por isso, ser considerada em cada contexto sócio-histórico. Dessa forma, a APS tem se mantido como um espaço rico de debates que ganham maior ou menor destaque em certos contextos, mas estão sempre presentes. 
Essa mesma perspectiva orienta a nossa compreensão do perfil social do trabalhador comunitário em saúde, cuja história está intrinsecamente associada à da APS, que tem como principal expressão no Brasil, hoje, a Estratégia Saúde da Família (ESF) na qual atua o agente comunitário de saúde (ACS).

Este trabalho procura recuperar e analisar elementos históricos relevantes para a constituição da APS e do trabalhador comunitário da saúde, por meio do exame da produção bibliográfica sobre o tema e do material documental produzido por instituições e organismos internacionais que influenciam o debate e que disputam a conformação das políticas de saúde no mundo e, especialmente, no Brasil.

\section{Território, atenção permanente e educação para a saúde no modelo dos health centers}

Segundo Cueto (2004), o termo 'atenção primária' foi, provavelmente, utilizado pela primeira vez no periódico Contact, da Christian Medical Commission, instituição criada nos anos 1960 por missionários médicos que atuavam nos países pobres e que, na década seguinte, estiveram intensamente articulados com a OMS para formulação de propostas para a saúde tendo a APS como base. Entretanto, a primeira formalização de propostas para um sistema de saúde consistente com a ideia posteriormente nomeada como atenção primária remete ao ano de 1920, quando o governo britânico publicou um documento conhecido como Relatório Dawson (Fausto e Matta, 2007). Nele encontra-se a proposta de organização dos serviços com base distrital, hierarquização em quatro níveis, em que o primeiro é formado por centros de saúde com atendimento pelo general practitioner (GP).

Ideias que posteriormente compuseram o conceito da APS estão presentes no Brasil, na reforma de 1925 que, em São Paulo, instituiu o modelo de centro de saúde, cujas atribuições eram: uniformizar o tratamento adequado de doenças transmissíveis, localizar focos de doenças e, principalmente, criar oportunidades para a educação sanitária dos pacientes e das respectivas famílias. Em certa medida, encontrava-se um contraponto à polícia médica, então vigente, ao se apresentar a ideia de 'consciência sanitária' e fazer da educação um elemento central da relação desses serviços com a comunidade (Castro Santos e Faria, 2002).

Foi nesse período que se iniciou o primeiro curso de educadoras sanitárias ou visitadoras (Faria, 2006), demonstrando que a atuação contínua, em conexão com os locais de moradia da população, já havia sido, no Brasil, um ponto de destaque nas propostas de serviços de saúde permanentes e não de ações pontuais, características das campanhas. Abriu-se oficialmente um espaço para que o setor saúde incorporasse trabalhadores não 
profissionais para realizar um trabalho de aproximação entre as ações de saúde e a população.

Apesar de revelar algumas peculiaridades, o modelo de centro de saúde brasileiro foi explicitamente inspirado no modelo norte-americano dos health centers. Em ambos os países, consolidava-se a ideia da atuação distrital, baseada na definição de um território e de uma população, da participação da comunidade e da 'educação para prevenir' (Castro Santos e Faria, 2002). No Brasil, sua implementação associa-se à atuação da Fundação Rockefeller, que participou do financiamento do Instituto de Hygiene de São Paulo, instituição influente na formulação de políticas de saúde, e modelou fortemente a educação médica e a formação em enfermagem, segundo os padrões norte-americanos (Oguisso, Campos e Santiago, 2009). A partir do programa de bolsas de estudo dessa fundação, expoentes do sanitarismo do Brasil e de vários outros países fizeram parte de sua formação na Universidade Johns Hopkins, o que repercutiu para a difusão de um modelo de ciência e administração sanitária no qual os centros de saúde tiveram destaque (Castro Santos e Faria, 2002).

Tanto no Brasil quanto nos Estados Unidos, esse modelo sustentava-se no entendimento de que o alcance de resultados mais efetivos na saúde, cuja compreensão restringia-se à ausência de doença, dependia da aproximação entre os serviços e a população. Nas palavras de Barreto, que esteve à frente do Departamento Nacional de Saúde durante alguns anos da Era Vargas e defendia o desenvolvimento de uma rede de centros de saúde com foco distrital, essa era uma forma de proporcionar à população "o atendimento em um mesmo local, e de uma só vez, de todos os seus interesses e necessidades em matéria de higiene" (Barreto, 1931 apud Castro Santos e Faria, 2002, p. 7).

Nos Estados Unidos, a década de 1930 ainda veria a proposta dos health centers se fortalecer, sobretudo por sua vinculação ao movimento dos distritos sanitários. O financiamento era em grande parte público, municipal, mas cabia ao centro de saúde coordenar as ações que incluíam as instituições privadas. Ainda assim, esses serviços eram percebidos como uma forma de concorrência com a produção de serviços pela iniciativa privada (Duffy, 1990). De acordo com Duffy, a redução da imigração, a melhoria das condições de vida, a mudança nos padrões do trabalho social e a oposição das associações médicas levaram, nos anos 1940, ao declínio contínuo de ambos os movimentos, que eram dirigidos às populações urbanas empobrecidas.

No Brasil, a continuidade do modelo dos centros de saúde é atribuída à existência de um grande contingente populacional com condições econômicas mais precárias e ao prestígio dos sanitaristas (Castro Santos e Faria, 2002), cada vez mais próximos do poder estatal.

Os conceitos sobre os quais se organizava a noção de atenção primária daquela época eram oriundos da Higiene, reconhecida como uma área de 
saber, interdisciplinar, que nos anos 1930 chegava a ser apresentada como a nova medicina, por meio da qual seria viabilizada a "aplicação de todo o conjunto das ciências na manutenção do bem-estar, mito de uma unidade do conhecimento em prol do bem viver, espaço que se superpõe e acompanha a vida, difusa no próprio espaço dos homens" (Arouca 2003, p. 114).

No marco da Higiene, a educação para a saúde associada ao modelo dos centros de saúde teria um caráter altamente normatizador, atuando nos mais diversos âmbitos da vida e em espaços institucionais como a escola, a fábrica e o domicílio. Apesar desse traço, existia a compreensão de que os centros de saúde eram unidades nas quais a saúde estava articulada à dimensão social e em interação com o meio. Embora essa forma de expressão possa parecer parte de um discurso mais atual, eram esses os termos utilizados, nos anos 1930, por sanitaristas como Paula Souza e Samuel Pessoa, que achavam necessária a distinção do papel de cada tipo de instituição, em particular os hospitais, centros de saúde e policlínicas (Castro Santos e Faria, 2002).

A educação sanitária como direcionador e a visita domiciliar como prática, aliadas ao direcionamento da atenção a segmentos populacionais excluídos do acesso aos serviços de saúde, tão presentes nas primeiras décadas do século XX, são retomadas nas propostas da medicina comunitária em meados da década de 1970 (Donnangelo e Pereira, 1976) e no Programa de Saúde da Família a partir dos anos 1990, com novas influências, entre elas a da educação popular em saúde que não necessariamente elimina a perspectiva higienista, mas oferece-lhe um contraponto.

Da mesma forma, percebemos que fundamentos presentes no discurso atual sobre APS já constituíam características do ensino de Higiene e Saúde Pública, que compunha os currículos médicos. A atividade de inspeção, por exemplo, compreendia

(...) um mapeamento da situação sanitária local e, ao mesmo tempo, fornecia ao Instituto de Higiene, dados sobre abastecimento de água, sistemas de tratamento dos esgotos, métodos de tratamento do lixo, estatísticas vitais, condições sanitárias das fábricas e habitações coletivas, higiene das escolas, mercados, matadouros e portos (Faria, 2005, p. 1.016).

A inclusão dessas atividades na formação médica demonstra uma percepção da vinculação entre problemas de saúde e condições de vida, ainda que não houvesse uma problematização do sistema de produção que dá origem às más condições de vida. A visão de educação em saúde não transcendia o controle da propagação de doenças e a difusão de hábitos, além de ser permeada pela individualização das responsabilidades. Para Arouca, a Higiene consistia em 
(...) uma visão de mundo ideológico que no conjunto de suas representações abstrai as causações para afirmar uma solução normativa, vinda da unidade das ciências, enquanto discursa sobre as alternativas de mudanças das condições de existência, dentro da própria estrutura que determina estas mesmas condições de existência (Arouca, 2003, p. 115).

O trabalho nos centros e nos postos de saúde, embora pretendesse abarcar várias dimensões da vida diretamente relacionadas à saúde, desenvolvia-se com base em uma perspectiva biomédica, com foco na profilaxia contra doenças infecciosas, na luta contra os vetores, na transmissão de informações sobre puericultura às mães - elementos marcantes no modelo Rockefeller.

Merhy (1992) diria que o modelo tecnoassistencial representado pelos centros de saúde baseava-se na corrente médico-sanitarista que entende a “causa-básica do processo saúde-doença como pertinente ao indivíduo (consciência sanitária) e única" (Merhy, 1992, p. 29). Ainda assim, esse era um modelo que se opunha ao campanhista, que tinha em dispensários e inspetorias sanitárias seu serviço prioritário, e que se filiava inteiramente às formas de intervenção propugnadas pelo pensamento bacteriológico, voltando-se ao atendimento de uma doença específica.

É importante lembrar que foi também na década de 1920 que, no Brasil, teve início o modelo de previdência social com as caixas de aposentadorias e pensões, passando a se estabelecer uma dicotomia entre as ações de saúde pública e de assistência e que, em certa medida, refletiam uma distinção e uma disputa entre a clínica e a saúde pública. Nesse contexto, os centros de saúde eram as organizações que representavam a assistência sanitária com base na perspectiva de uma assistência básica, enquanto a medicina previdenciária foi institucionalmente representada pelos hospitais (Campos, C., 1999).

As décadas de 1930 e 1940 ainda veriam, principalmente em São Paulo e na capital federal (Rio de Janeiro), mas também em outros estados, a expansão desses centros de saúde, aos quais se juntaram os postos e subpostos de higiene, postos especializados e postos itinerantes. 4 Nessas unidades a educadora/visitadora sanitária era imprescindível e sua ausência determinava que um posto passasse à condição de subposto (Castro Santos e Faria, 2002). A definição de um território, o distrito sanitário, ao qual se vinculavam o centro e os postos de saúde, também vingara, de modo que, em 1942, em São Paulo, haviam sido constituídos 93 distritos sanitários (Campos, C., 1999).

Ideias estruturantes do modelo dos centros de saúde são retomadas em princípios organizativos da atenção primária à saúde, de um modo geral, e da ESF e do trabalho do ACS no Brasil. Nesse sentido as ideias mais significativas são: a centralidade de um trabalhador que não é da categoria médica nem da enfermagem - com papel de articular conhecimentos dessas áreas com os da educação -, a prática da visita domiciliar e a definição de um território 
de atuação. Segundo Carlos Campos (1999), o esvaziamento dessa organização sanitária, mais afinada com o que hoje chamamos de atenção primária à saúde, viria a partir de 1939, em função de decreto do então presidente Getulio Vargas e do ministro de Educação e Saúde Gustavo Capanema, que determinou a transferência dos centros de saúde vinculados ao Departamento Nacional de Saúde (DNS) para a prefeitura do Distrito Federal (Campos, C., 1999).

Ainda que houvesse uma divisão hospitalar no DNS, a disputa em torno de uma racionalidade de organização da assistência à saúde ocorria entre o modelo com base na assistência básica, distrital e permanente - representado na época pelos centros de saúde - e o modelo campanhista - verticalizado e especializado - que organizou os serviços nacionais por doença (lepra, febre amarela, malária, entre outras).

Por sua vez, a transferência de gestão para a prefeitura representou, à época, perda de prestígio e poder para os centros de saúde que pretendiam instituir-se como um modelo de organização sanitária de abrangência nacional (Campos, C., 1999).

\section{Expansão de cobertura, aproximação com a comunidade e os trabalhadores comunitários}

No âmbito de um acordo entre Brasil e Estados Unidos, promovido por uma agência coordenada por Nelson Rockfeller, em 1942, foi criado o Serviço Especial de Saúde Pública (Sesp) que atuou até 1960, quando foi substituído pela Fundação Sesp. Vinculado ao contexto de proteção das áreas de produção de matéria-prima para fins militares, especialmente da Amazônia e Vale do Rio Doce, o Sesp teve sua atuação expandida para o Nordeste, embalada pelos preceitos das políticas desenvolvimentistas da época. No governo Vargas, período em que foi criada, a instituição já apresentava o propósito de atuar fortemente na formação de trabalhadores de saúde, em particular médicos, enfermeiras, engenheiros sanitários e 'profissionais intermediários', como as visitadoras sanitárias (Campos, A., 2006). O Sesp teve papel importante ao expandir a autoridade pública, tomando o campo da saúde como base. Além de responder a questões de saúde, assumindo a educação sanitária como eixo, os serviços tornavam-se instrumentos de vínculo político com a população do interior e, desse modo, produtores de uma nacionalidade (Campos, A., 2006).

As visitadoras sanitárias no contexto sespiano diferiam daquelas que se vincularam ao modelo dos centros de saúde nas áreas urbanas dos anos 1930. Por lei, estas últimas deveriam ser diplomadas pela Escola Normal, o que nesse período histórico indicava uma posição social de prestígio. Além desse pré-requisito, elas recebiam uma formação de um ano e meio, 
em tempo integral, podendo assim ascender ao cargo de educador sanitário no serviço público (São Paulo, 1926). Nas décadas de 1940 e 1950, o Sesp, que na época era o ator institucional mais relevante na saúde pública, encarava a educação sanitária como uma atividade transversal aos seus diversos profissionais. O investimento na formação sanitária era mais difuso, incluindo, por exemplo, os professores primários para atuação nas escolas. Entretanto, esta aposta na educação sanitária não resultou em proporcionar maior densidade a essa formação que, em geral, era bem abreviada.

Silva e Dalmaso (2002) incluem as visitadoras sanitárias do Sesp num grupo genericamente denominado 'pessoal auxiliar', que tem traços em comum com o perfil atribuído aos ACS. A atuação das visitadoras influenciou a formulação de propostas nos programas com uma vertente de reorientação da atenção à saúde no Brasil. Essas trabalhadoras eram selecionadas entre os moradores de uma área, mas o seu trabalho era realizado em outra localidade. O curso de capacitação, com conteúdos eminentemente práticos, durava seis meses em regime integral e o requisito de escolaridade era o ensino primário completo. As atribuições eram levar instrução sanitária, na perspectiva de substituir os saberes populares pelos de caráter científico, e provocar a incorporação de hábitos condizentes com esses preceitos. $\mathrm{Na}$ divisão do trabalho estabelecida no Sesp, as visitadoras sanitárias atuavam na relação com as pessoas, e os guardas sanitários interferiam nas condições materiais do ambiente (Teixeira, 2008).

O entendimento de que a doença era um obstáculo primordial ao desenvolvimento pautava as políticas de saúde mais amplas e também as estratégias por meio das quais as práticas sanitárias eram postas em curso. Em uma atitude influenciada pelo ingresso das ciências sociais na saúde em geral e no Sesp, a mobilização local tornou-se um lema, indicando a necessidade de identificar pessoas influentes nas comunidades para potencializar o trabalho educativo, de modo a promover um sentimento de responsabilização em cada indivíduo pela sua falta de saúde (Renovato e Bagnato, 2011).

Na década de 1960, a ideia de um trabalhador recrutado na comunidade fez-se presente na 3a Conferência Nacional de Saúde (CNS), realizada em 1963. Nela evidenciaram-se a preocupação em assumir o desenvolvimento econômico do país e a inadequação do modelo de organização e administração do sistema de saúde como pano de fundo da análise do contexto sanitário. A atuação contínua e apropriada nos diversos níveis - federal, estadual e municipal - era tomada como premissa para a melhoria do estado de saúde da população. O modelo campanhista teve alguns de seus méritos reconhecidos, mas era apresentado como um agravante do planejamento concebido e implementado verticalmente e distanciado das realidades locais.

Considerar essas realidades implicava definir e pôr em curso políticas locais. Tendo em vista a impossibilidade de "colocar um médico ou sequer 
um enfermeiro qualificado em cada município ou localidade do interior", o equacionamento das necessidades de atendimento deveria se dar pela incorporação do trabalhador comunitário, "promovendo a utilização em larga escala de pessoal técnico de menor qualificação" com capacidade de desempenhar serviços básicos mínimos (Niterói, 1992, p. 155). Sobre as características desse trabalhador, o relatório da $3^{\text {a }}$ CNS orienta para o "recrutamento no seio da própria comunidade a qual vão servir, tendo em vista sua fixação perfeita ao local, sem qualquer desajuste de ordem social, técnica ou econômica, percalços sempre presentes em relação aos elementos alienígenas" (Niterói, 1992, p. 156).

A esse argumento de caráter cultural associa-se outro de caráter gerencial que determina a conformação do perfil desse trabalhador. Trata-se do baixo investimento em formação, pois a proposta de qualificação técnica está "condicionada ao meio onde vai exercer suas atividades", portanto a seleção na comunidade traria como vantagens evitar não somente o "desnível de pagamento do técnico em relação à capacidade de pagar do meio", mas também "a fuga do técnico de seu próprio meio" (Niterói, 1992, p. 156). Ao ganhar dimensão nacional e vincular sua origem à comunidade, a proposta desse educador sanitário distingue-se daquela implementada em São Paulo nos anos 1930 e caracteriza-se pela baixa qualificação e remuneração. Cabe notar que esses são elementos que persistem até hoje nas discussões sobre o perfil social dos ACS e demonstram a compreensão do trabalho do agente como algo simples.

Politicamente, o golpe militar de 1964 interrompeu o processo de fortalecimento de uma rede básica e enfraqueceu ainda mais o modelo dos centros de saúde que já vinha em declínio. André Campos (2006) destaca os avanços científicos e tecnológicos da medicina e seus desdobramento (novas drogas, técnicas e produtos) como elementos que trouxeram o hospital para o centro do sistema de saúde. Isso se refletiu, por exemplo, na estrutura física cada vez mais precária e na escassez de quadros profissionais dos centros de saúde, com os sanitaristas sendo absorvidos pelas estruturas federais (Campos, C., 1999, p. 87).

Nas décadas de 1960 e 1970, no âmbito dos programas de extensão de cobertura, dentre os quais se pode destacar o Plano de Interiorização das Ações de Saúde e Saneamento (Piass), encontramos alguns elementos que também remetem às concepções que sustentam a APS, como a aproximação com a comunidade, o desenvolvimento de ações de prevenção e assistência e a inserção de um trabalhador recrutado nas próprias comunidades, caracterizado como sendo de nível auxiliar (Silva e Dalmaso, 2002).

O contexto político - ditadura militar, com suspensão de direitos democráticos e da participação política - e o contexto econômico - desenvolvimento desenvolvimento atrelado ao financiamento público do setor 
produtivo e crescimento da presença do capital internacional - determinaram que o projeto se difundisse nos espaços em que não representasse ameaça aos interesses do setor privado e conveniado. O setor expandia-se estruturado por uma lógica médico-curativa, sustentada pelo modelo hospitalocêntrico, associado à concentração de equipamentos médico-hospitalares.

Entretanto, esse processo não aconteceu sem resistências. Ao final da década de 1970 e durante os anos 1980, setores populares da sociedade civil, aliados a técnicos da saúde, organizaram-se em um movimento social contra-hegemônico que ficou conhecido como Reforma Sanitária. Considerando a impossibilidade de tratar de modo homogêneo esse movimento, optamos por iniciar a discussão sobre APS por meio do relatório da 8a Conferência Nacional de Saúde (Brasil, 1986a).

A ideia de um modelo de atenção que possa ser associado a APS não figura diretamente nesse texto, mas sim a ênfase na ampliação do acesso, visando a sua universalização, a descentralização/municipalização e hierarquização do sistema e o desenvolvimento da promoção à saúde. Tais elementos posteriormente se estabelecem como condições para o desenvolvimento posterior da ESF no Sistema Único de Saúde (SUS). Quanto aos trabalhadores comunitários, no relatório final da $8^{\mathrm{a}} \mathrm{CNS}$, consta a recomendação de “incorporação dos agentes populares de saúde como pessoal remunerado, sob a coordenação do nível local do Sistema Único de Saúde, para trabalhar em educação para a saúde e cuidados primários" (Brasil, 1986a, p. 12).

Ainda em 1986, no relatório final da la Conferência Nacional de Recursos Humanos em Saúde, os ACS são mencionados na parte relativa às proposições. O documento defende que se reveja "a questão do agente comunitário e sua inclusão, sem distorções, como articulador entre comunidade e os serviços de saúde, evitando o confuso repasse de responsabilidades" e recomenda que sejam realizadas reuniões estaduais desses trabalhadores (Brasil, 1986b, p. 48). A abordagem sobre os agentes comunitários era restrita e o texto não possibilita amplas reflexões sobre o modo como esse trabalhador era pensado no conjunto de mudanças que se propugnava no âmbito da Reforma Sanitária.

\section{APS: disputas permanentes em conjunturas diferenciadas}

No cenário internacional, Cueto (2004) assinala a visibilidade de diversas situações como catalisadoras de um interesse maior em torno das ideias de atenção primária. A experiência chinesa dos Médicos de Pés Descalços, as consequências do processo de descolonização de países africanos e as Missões da Comissão Médica Cristã, com atuação em diversos países, inclusive na África, foram algumas delas. 
No plano institucional, a ascensão à diretoria da OMS e as duas reeleições de Halfdan Mahler, cuja trajetória incluía ações de combate à tuberculose no Equador e na Índia e que "tinha um carisma pessoal marcante" (Cueto, 2004, p. 1.865), contribuíram para dar continuidade aos projetos iniciados antes dele e que envolviam o desenvolvimento de serviços básicos de saúde. Em relato sobre sua própria história, a OMS (WHO, 2008) indica os anos 1960 como aqueles em que a OMS e a Unicef, em conjunto, sistematizaram indicativos técnicos para a organização de serviços básicos de saúde, definidos como

(...) uma rede de serviços periféricos e intermediários (...) capazes de oferecer uma seleção de funções essenciais à saúde de uma determinada área, garantindo o acesso da população a pessoal de nível auxiliar e a profissional competente para desempenhar as funções selecionadas (WHO, 2008, p. 117, tradução nossa).

A respeito dos profissionais que deveriam compor as equipes desses serviços básicos, pairou uma indefinição. A OMS e a Unicef optaram por aliar-se à ideia de que cada país deveria responder a essa questão de acordo com a sua própria disponibilidade de recursos (WHO, 2008).

Durante os anos 1970 intensificaram-se as reuniões e a produção de documentos que elegiam a expansão de cobertura com base nos serviços básicos de saúde como tema de debate. A OMS e a Unicef discutiam as diferentes formas de apoiar os países nessa expansão, visando, sobretudo, à população que, em grande medida, permanecia sem acesso aos serviços. Em 1975, a OMS publica o documento Alternative Approaches to Meeting Basic Health Needs of Populations in Developing Countries (WHO, 1975), que se torna notório neste debate, e no qual o termo 'alternativas' referia-se aos programas verticais, que focalizavam uma única doença.

Essa publicação acentua a crítica ao modelo ocidental industrializado de sistema de saúde, alertando para as diferenças entre os problemas de saúde enfrentados pelas populações dos países em desenvolvimento. Experiências em APS de países como Bangladesh, China, Cuba, Índia, Nigéria foram divulgadas (Cueto 2004), e o documento tornou-se uma referência para as discussões sobre a APS nos fóruns institucionais internacionais sobre saúde até a Conferência de Alma-Ata, em 1978, que se torna um [novo] marco nessa questão.

A I Conferência de Cuidados Primários de Saúde, que ficou conhecida pelo nome da cidade que a sediou, Alma-Ata, é um marco tão significativo na história da APS que não é raro encontrar-se a opção de tratar da APS a partir dela. Nesse evento produziu-se uma conceituação de atenção primária à saúde que se tornou internacionalmente conhecida. No relatório da conferência, lê-se que APS consiste em 
Cuidados essenciais baseados em métodos práticos, cientificamente bem fundamentados e socialmente aceitáveis e em tecnologia de acesso universal para indivíduos e suas famílias na comunidade (...). Além de serem o primeiro nível de contato de indivíduos, da família e da comunidade com o sistema nacional de saúde, aproximando ao máximo possível os serviços de saúde nos lugares onde o povo vive e trabalha, constituem também o primeiro elemento de um contínuo processo de atendimento em saúde (OMS/Unicef, 1979, p. 2).

A conceituação genérica que a APS adquiriu no relatório de Alma-Ata foi um reflexo da dificuldade de superar divergências em relação aos elementos que deveriam constituí-la. Uma vez conformada em termos amplos, caberia a cada país estabelecer um processo por meio do qual se definisse a APS mais condizente com cada realidade (Mello, Fontanella, Demarzo, 2009).

Conill (2008) destaca a integração dos serviços locais em um sistema nacional, a participação da população, as ações intersetoriais e a relação da saúde com o desenvolvimento econômico como os principais elementos da APS que a OMS pretendia difundir naquele momento. Para Cueto (2004), havia ainda outras duas ideias-chave da conferência: tecnologia apropriada e oposição ao elitismo médico. A questão da tecnologia apropriada se vincula à crítica ao modelo dos hospitais urbanos, em torno dos quais pairava a aura de solução para as questões de saúde, e apontava para a necessidade de postos nas regiões rurais. A posição contra o elitismo médico questionava a superespecialização dos profissionais de saúde, colocava a questão dos trabalhadores leigos, a participação da comunidade e a valorização das práticas populares de cuidado (Cueto, 2004).

No final dos anos 1980, o Banco Mundial, que já interferia em questões da saúde desde os anos 1960, entra em cena explicitando sua política para os sistemas de saúde dos países em desenvolvimento, e o faz gerando impacto sobre os contornos que delimitariam a APS.

Em primeiro lugar, questionava a associação entre o princípio da universalidade do direito à saúde e a responsabilidade do Estado pelo financiamento e pela prestação da atenção à saúde. Em documento de 1987, o Banco propõe uma agenda de reformas para a saúde (World Bank, 1987), partindo da premissa de que os diferentes problemas que esses países enfrentam no setor são atribuídos, em parte, à determinação dos governos de cobrirem integralmente os custos de saúde com recursos públicos para toda a população.

Nesse mesmo documento o financiamento da atenção primária é discutido, afirmando-se a impossibilidade de se viabilizar financeiramente o modelo da APS somente com base em uma revisão do modelo tecnoassistencial, mediante a alteração da posição de centralidade do hospital no sistema. Para este problema, dois encaminhamentos são priorizados: identificação da parcela da população capaz de pagar por serviços de saúde e a destinação 
de serviços para os mais pobres, a serem financiados também com os recursos provenientes dos serviços pagos (World Bank, 1987).

Já em 1979 havia um movimento de oposição à abrangência que a APS tomou em Alma-Ata. Em um simpósio realizado em 1979, em Bellagio (Itália), com financiamento da Fundação Rockefeller e participação do presidente do Banco Mundial, McNamara, o conceito de APS seletiva foi defendido, tendo por referência a definição de procedimentos pautados pela relação custo-benefício e como objetivo principal o enfrentamento das doenças infecciosas. Em documento de 1995, divulgado pelo Banco Mundial e produzido por um de seus consultores, 16 anos depois de Alma-Ata, encontra-se uma síntese contundente da APS seletiva:

O conceito de atenção primária em saúde implica oferecer um número limitado, simplificado e barato de tecnologias de saúde, para um amplo número de pessoas em situação de necessidade e por meio de um staff paramédico, habitantes das comunidades (Heaver, 1995, p. 5, grifos do autor).

No final dos anos 1980, o Banco Mundial publicava análises sobre o setor saúde no Brasil, mas, em documento de 1993, explicitou de forma marcante as preocupações quanto aos compromissos, classificados como 'idealistas', assumidos na Constituição brasileira de 1988 e apresentou indicativos para contornar os problemas que previa para o cenário brasileiro. Rizzotto (2000) analisa que o Programa de Agentes Comunitários de Saúde (Pacs) e o Programa de Saúde da Família (PSF), implementados na perspectiva da APS seletiva, representam a assimilação das recomendações do Banco Mundial no Brasil.

Ao contrário do enfoque seletivo da APS, o enfoque que toma a APS como princípio orientador do sistema de saúde aponta para um modelo de maior complexidade, pois a ele vinculam-se os próprios princípios da APS, valores, elementos estruturantes e funcionais (Opas, 2005). Neste segundo enfoque, existe um conjunto de compromissos e orientações que abarcam os diversos planos de implementação de uma política de saúde, incorporando temas relativos ao financiamento e à própria posição do Estado como executor de ações, fomentando o debate sobre a relação público-privado.

\section{APS e Estratégia Saúde da Família}

Pela via das políticas públicas, o reingresso das concepções de APS no Brasil ocorreria com maior força a partir de 1991, com a criação no âmbito governamental do Pacs e, em 1994, do Programa de Saúde da Família. Estes programas instituem o agente comunitário no SUS, conferindo-lhe papel estratégico no seu desenvolvimento. 
Viana e Dal Poz (2005) registram que nesse período tornavam-se mais evidentes os problemas no quadro sanitário, dado que padrões epidemiológicos associados às doenças infectocontagiosas adicionavam-se as crônico-degenerativas e acidentes externos, gerando um tipo de demanda incapaz de ser equacionada nos sistemas de serviços disponíveis.

Esse conjunto de questões articuladas a problemas de gestão configurou o que se chamou de 'crise da saúde'. Essa crise impulsionou a implementação de reformas incrementais definidas, pelos autores, como o conjunto de modificações no desenho e na operação da política (Dal Poz e Vianna, 2005).

As normas operacionais básicas (NOB), particularmente as NOB 01/93 e NOB 01/96, tiveram impacto nessa reforma. A primeira, pelo que representou de avanço para a descentralização, e a segunda, por alterar a forma de gestão do sistema, sendo notável a criação do Piso da Atenção Básica e de incentivos financeiros para várias ações, dentre as quais o PSF/ESF e o Pacs. Viana e Dal Poz (2005) consideram que o PSF e o Pacs condensaram um movimento de mudança do modelo assistencial em um cenário no qual se identificava um vazio programático.

Inicialmente concebido para reverter os índices apresentados pelos indicadores de morbimortalidade de segmentos populacionais excluídos da atenção à saúde, predominantemente em meio rural e urbano de baixa complexidade, com ações voltadas ao grupo materno-infantil, o Pacs se concentrou em atividades educativas desenvolvidas pelo ACS.

O agente comunitário atuava em um território definido, sob a supervisão de um enfermeiro. Era responsável por um determinado número de domicílios que visitava regularmente, acompanhando e registrando as condições de saúde, fornecendo orientações preventivas e difundindo técnicas simples e de alto impacto nos indicadores de saúde, como terapia de reidratação oral, aleitamento materno e incentivo à imunização, que compõem o pacote GOBI - sigla, em inglês, que combina os procedimentos growth monitoring (acompanhamento do crescimento), oral rehydration (reidratação oral), breast-feeding (aleitamento materno) e immunization (imunização) - proposto pela Unicef nos anos 1980, nos marcos da APS seletiva. A preparação do ACS para o trabalho ocorria em serviço e era de responsabilidade do enfermeiro-supervisor.

O PSF amplia as características do Pacs, agregando uma equipe, composta basicamente por médico, enfermeiro, auxiliares, técnicos de enfermagem e os ACS, vinculados a uma unidade básica de saúde, que abrange um território e um número definido de domicílios, distribuídos entre os ACS, segundo uma lógica de divisão territorial. Os ACS cumprem funções de mediação entre essas equipes, a unidade básica de saúde, os saberes que circulam nesses espaços e a população atendida. No processo de trabalho dos ACS, intensifica-se a produção de informações, e suas ações passam 
a integrar o planejamento das ações da equipe e da unidade básica de saúde, visando ao cumprimento de metas relacionadas aos programas de saúde pública.

Em desenvolvimento posterior, o Pacs e o PSF integram a Estratégia Saúde da Família, que ganha o status de modelo de reorientação da atenção básica e articula ações de prevenção, vigilância e promoção da saúde nos territórios adscritos, com o propósito de resolver a maior parte dos problemas de saúde da população. Nos anos 2000, essa estratégia amplia-se para os grandes centros urbanos, fortemente apoiada por recursos do Banco Mundial e do Ministério da Saúde, alocados por meio do Projeto de Expansão e Consolidação da Saúde da Família (Proesf).

\section{O trabalho do ACS}

Os ACS do Brasil são representativos de um grupo genericamente denominado, na literatura internacional, de community health workers ( $\mathrm{CHW}$ ) ou, em português, trabalhadores comunitários de saúde. Estes se configuram, primeiramente, como uma resposta às situações de grandes carências e ausência de serviços de saúde (Walt, 1990).

A relação com a expansão de cobertura para áreas rurais está na base de experiências com trabalhadores comunitários, como a da Rússia que, desde o século XIX, treinava os egressos das escolas para tais atividades. Essa relação está presente também no final dos anos 1960, na China, com os 'médicos de pés descalços' - um programa nacional que, além da cobertura às áreas afastadas, teve como característica o envolvimento de membros das comunidades (Walt, 1990).

O processo de luta pela independência das colônias africanas, que gerou a evasão de profissionais de saúde desses locais, também acarretou a necessidade de articular novas formas de cuidado que não fossem centradas na assistência médica. Adotou-se, então, o treinamento de membros da população para atuar não apenas na prevenção, mas também na assistência à saúde.

Mocambique e Argélia, na segunda metade dos anos 1970, foram países em que a reorganização das ações de saúde aconteceu por meio da criação de alternativas à assistência médica tradicional em associação à valorização do autocuidado. Em Cuba, onde a revolução socialista também sofreu com a perda de um número importante de médicos, instituiu-se uma nova forma de organizar os serviços, com policlínicas, serviços básicos e a participação da comunidade (Walt, 1990).

Mesmo considerando que essas experiências ocorreram em diferentes contextos político-sociais e produziram formas mais ou menos democráticas, 
participativas, inclusivas e transformadoras de organização da saúde, pode-se dizer que foram os resultados dessas experiências que ajudaram a difundir uma forma de conceber e implementar parte importante das ações de saúde no âmbito da atenção primária. Essa configuração da APS, na qual a participação de um trabalhador oriundo das comunidades, não pertencente às categorias tradicionais da saúde, ganha centralidade na organização das ações e serviços de saúde, vem se consolidando em diversos países da América Latina e da África.

Diante dessa realidade, de expansão da APS fortemente associada ao CHW, faz-se necessário conhecer o percurso histórico de constituição desse trabalhador e identificar as tensões e disputas que se colocaram em torno da definição do seu trabalho, suas atribuições, sua formação e sua inserção no sistema de saúde.

Cabe destacar a participação de organismos internacionais na definição do processo de incorporação do CHW na APS, que se encontra já no primeiro documento produzido pelo Banco Mundial especificamente para a área da saúde, denominado Health: sector policy paper (World Bank, 1975).

No documento defende-se que, para ser eficiente, o sistema de cuidado em saúde deve estar, tanto geográfica quanto culturalmente, muito próximo da comunidade a que serve e deve gozar da total confiança dela. Essa argumentação antecede a proposição de como deve ser o trabalhador comunitário de saúde, parecendo construir a base propositiva de certas características desse trabalhador. Nele, lemos:

O trabalhador comunitário de saúde, num sistema reformado, deve residir na comunidade a que serve e ser respeitado por esta. Ele deve estar integrado à sociedade local de forma que possa identificar doenças antes que se dê o contato do paciente com o posto de saúde. Visitas domiciliares de rotinas podem ser requeridas para assegurar tais avaliações [das condições de saúde]; em alguns casos, as instituições políticas, sociais e religiosas locais podem oferecer oportunidades para a vigilância contínua das condições de saúde da comunidade. (...)

A escolha [desse trabalhador] deve refletir atitudes culturais e saber ler e escrever não seria um requisito essencial (World Bank, 1975, p. 43, tradução nossa).

O documento prossegue descrevendo as áreas em que o trabalhador deveria ser treinado, indicando prioridade para as atividades preventivas, mas admitindo práticas clínicas simples, para as quais seria desejável treinamento limitado, de forma a garantir tempo adequado para o trabalho ambiental e preventivo. Suas responsabilidades incluem oferecer orientação nutricional a mães de crianças mal nutridas, prover imunização e encorajar o planejamento familiar, além de organizar esforços comunitários em saúde ambiental, abastecimento de água e esgoto. A maior virtude desse trabalhador seria 
"sua origem socioeconômica e cultural - a mesma que a das pessoas a quem ele serve - e também a sua capacidade de interagir com elas num estilo e numa linguagem que elas entendam" (World Bank, 1975, p. 44, tradução nossa).

Em maior ou menor grau, tais considerações, que como vimos já estiveram presentes em décadas anteriores, passaram a integrar a formulação de políticas de saúde que promovem a participação dos trabalhadores comunitários de saúde como elemento central da reorganização das ações e serviços no marco da APS. No Brasil, no âmbito da Estratégia Saúde da Família, esse trabalhador foi denominado agente comunitário de saúde (ACS).

As ideias que conformaram a proposta de atuação desse trabalhador em muito refletem essas orientações, resultando em uma série de contradições no que diz respeito à gestão, à organização do processo de trabalho e à formação dos ACS.

No Brasil, a contratação remunerada de agentes que atuavam na saúde foi uma das indicações do relatório da $8^{\text {a }}$ Conferência Nacional de Saúde, no item referente aos "princípios que devem reger o novo sistema" (Brasil, 1986a, p. 12). Diferentemente dos textos anteriormente citados, esse documento se constrói baseado num ideário político que compreendia a reforma da saúde como um elemento central de um projeto de transformação da sociedade.

Em 1991, quando se dá a incorporação formal do ACS em um programa de âmbito nacional, inicialmente o Pacs e posteriormente o PSF (1994), duas questões importantes de caráter socioeconômico estão imbricadas no contexto de formulação desses programas. Trata-se do desemprego estrutural característico da crise do sistema capitalista que predominou nas décadas de 1980 e 1990 e da retração da face pública do Estado, marca da reforma neoliberal que redesenhou o papel do Estado na sociedade brasileira. Essas questões geraram respostas em vários âmbitos da atuação estatal, das quais se destacam, no caso dos ACS, a política de fomento a programas de geração de renda para integrantes de estratos populacionais com pouca possibilidade de inserção num mercado de trabalho restrito e a política de redução de custos da atenção à saúde (Durão et al., 2011).

Morosini (2010) indica que essas iniciativas estão na base do equacionamento de uma contradição existente no fato de o PSF desenvolver-se e promover a ampliação de cobertura na área da saúde, ou seja, ampliação de direitos, numa conjuntura de restrição da participação direta do Estado nas políticas sociais, notadamente na prestação de serviços públicos.

Segundo a autora, essa contradição foi equacionada por três elementos que marcaram a Estratégia Saúde da Família: a simplificação do pacote de atenção oferecido, a precarização do vínculo de trabalho da equipe, especialmente do ACS, e o esvaziamento da sua formação. A formação simplificada, associada aos vínculos precários, configuram as principais condições limitantes para o processo de qualificação profissional desse trabalhador (Morosini, 2010). 
Pode-se dizer, então, que houve uma ampliação restrita do direito da população brasileira à saúde, com subtração de direitos dos trabalhadores da atenção primária.

A precarização incidiu sobre os trabalhadores da Estratégia Saúde da Família de uma maneira geral, mas teve efeitos diferenciados sobre os vários trabalhadores, diferindo em função de sua qualificação profissional, isto é, sua formação (duração, prestígio social do certificado correspondente), o valor social atribuído ao trabalho e ao trabalhador refletido, por exemplo, nas diferenças salariais entre os grupos profissionais (Morosini, 2010).

Nesse contexto, os ACS, durante a maior parte de sua participação na Saúde da Família, precisavam somente residir na comunidade em que atuariam, saber ler e escrever, ter espírito de liderança e solidariedade e disponibilidade de trabalho de 40 horas semanais (Morosini, 2010). ${ }^{5}$

No mesmo documento de 1995, no qual o Banco Mundial trata da concepção seletiva de APS, estão presentes concepções sobre o trabalho em saúde que geram indicações para a definição do perfil dos CHW:

Argumentamos anteriormente que, cedo ou tarde, a abordagem do pacote padrão da APS incorpora a necessidade de responder, de modo diferenciado, a um padrão diversificado de doenças. Os governos respondem a isso de dois modos principais: primeiro podem treinar trabalhadores da APS em um campo maior de tarefas. Entretanto, a experiência de campo nos mostra que os trabalhadores localmente recrutados não podem absorver e oferecer uma variedade ampla de intervenções dada sua educação limitada. O segundo modo de ampliar as intervenções seria aumentar o quadro de pessoal, com pessoas de maior escolaridade. Entretanto não é possivel recrutar esses trabalhadores nas favelas onde eles deverão trabalhar. Além disso, pessoas com status social mais elevado teriam, pelos clientes locais, baixa aceitabilidade. Teriam também que ser mais bem pagos do que os trabalhadores das comunidades. Deste modo, a estratégia poderia se tornar inviável em ampla escala ou poderia requerer um decréscimo da relação trabalhador x cliente (Heaver, 1995, p. 12, grifos do autor, tradução nossa).

No caso dos ACS no Brasil, a escolarização requerida ao trabalho só é modificada com a criação da profissão, no texto da lei n. 10.507/2002, que passa a exigir o ensino fundamental e prevê um curso de qualificação inicial, o que permanece na legislação atual - lei n. 11.350/2006 (Brasil, 2006a). Apesar de ter sido publicado, em 2004, o Referencial curricular para curso técnico de agente comunitário de saúde (Brasil, 2004), a formação técnica dos ACS ainda é uma realidade distante para a maior parte desses trabalhadores que lutam tanto por sua formação quanto por formas de vinculação que lhes assegurem os direitos associados ao trabalho. 
Como vimos, a base da argumentação em favor da qualificação profissional restrita, com formação simplificada e vínculos precarizados está dada, formalmente, desde a III Conferência de Saúde, em 1963, e no documento Health: Sector Policy Paper (World Bank, 1975), onde se encontram as orientações para o CHW. Foi respaldada também em outras iniciativas de organismos internacionais.

Uma participação importante nesse processo é a da OMS que, com base na inserção dos CHW como um elemento das estratégias de fortalecimento da APS, promoveu uma série de encontros para a troca de experiências entre os países que desenvolviam esse tipo de programa.

O primeiro encontro politicamente relevante, promovido pela OMS e Unicef para tratar do tema dos CHW, ocorreu na Jamaica, em 1980, e evidenciou a amplitude e a falta de precisão da definição do que seria um trabalhador comunitário de saúde (WHO, 1989). Constatou-se uma variação expressiva entre os vários países que participaram do encontro, especialmente quanto à remuneração e à escolaridade do CHW. No que tange à remuneração, observava-se desde trabalhadores assalariados, com ou sem direitos previdenciários garantidos, a outros que recebiam pequenas remunerações ou, até mesmo, trabalhavam como voluntários. O nível de escolaridade requerido ia do nível médio a nenhuma escolaridade, e a qualificação oferecida variava entre seis meses e dois anos. Na maior parte dos países, os programas já tinham um caráter nacional (Walt, 1990).

Segundo Walt, nos processos de discussão visando à definição do que seria um $\mathrm{CHW}$, acabou prevalecendo uma perspectiva reducionista que o caracteriza como um trabalhador morador da comunidade, sem expectativas de se mudar da comunidade onde atuaria e com um treinamento abreviado. Esse trabalhador poderia ou não receber remuneração, e, além disso, não estaria prevista a oportunidade de promoção a posições mais elevadas.

Temos de registrar aqui que essas compreensões sobre o perfil social do ACS não são meramente subjetivas e, sim, mecanismos da política que trazem repercussões em diversos níveis. No Brasil, um requisito que sustentou a contratação indireta do ACS pelo poder local foi a obrigatoriedade de residência na comunidade, o que contraria os princípios universalizantes do concurso público. 6 O requisito de que esse trabalhador fosse um representante da comunidade e estivesse a ela vinculado socioculturalmente acabou tornando-se um argumento contrário à sua formação profissional (Morosini, 2010).

Os programas que se estruturam com base nesse trabalhador, entretanto, enfrentam uma contradição inconciliável: ao mesmo tempo em que apontam para uma visão reduzida da qualificação do CHW, mantêm grandes expectativas sobre o que poderia ser incluído no rol de suas atividades. Por meio de seu trabalho, o CHW deveria reunir capacidades para realizar ações de 
promoção e prevenção em saúde que oferecessem resultados mensuráveis pelos indicadores tradicionais de avaliação e, em vários casos, ser um 'agente de mudança', mediante uma ação de mobilização social apoiada nos referenciais da educação popular.

Como agente de mudança, o CHW contribuiria para recolocar a questão da saúde no processo mais amplo das condições de vida, participando da construção de uma visão crítica sobre a relação saúde-doença e sua articulação com o sistema de produção e conformação das desigualdades sociais. Para várias partes do mundo, Paulo Freire proporcionou o aporte teórico que tinha nas categorias de conscientização crítica e práxis de duas bases fundamentais de seu pensamento. Tratar da importância e apropriação do Freire na educação em saúde e na prática dos trabalhadores comunitários merece um estudo específico. Destacamos apenas que afirmar a educação como um processo em favor da libertação, e associá-lo à ideia de mobilizar, em cada sujeito individual e coletivo, uma posição crítica diante de suas condições de vida e das possibilidades de ação transformadora, sustenta alguns eixos que legitimam o trabalho do ACS. Especificamente no Brasil, a educação popular em saúde é um campo de reflexão e práticas no qual o pensamento freireano difundiu-se e tem contribuído com formas mais democráticas e participativas de compreensão do trabalho e da formação dos ACS.

Com uma análise centrada no contexto do PSF, Fonseca e colaboradores (2012) afirmam que o trabalho do ACS se diferencia do trabalho dos demais profissionais da Equipe de Saúde da Família, uma vez que seu potencial de valorização está ancorado na dimensão educativa, enquanto os outros profissionais encontram na clínica um campo de práticas de validação de seu lugar no sistema de saúde. Entendemos também que é essa dimensão, aliada à mobilização social, que confere originalidade à sua inserção no âmbito do SUS, visto que trabalhadores de nível médio com formação para atuar com foco nas práticas biomédicas já tinham no auxiliar e no técnico de enfermagem um representante tradicional. Tal perspectiva também coloca em segundo plano a dimensão administrativa do trabalho do ACS, embora esteja a ela relacionada boa parte de suas tarefas (Bornstein e Stotz, 2008).

A compreensão do trabalho do ACS como eminentemente educativo encontra respaldo entre os documentos e as concepções dos profissionais da saúde, mas não expressa um consenso em torno da identidade desse trabalho. David (2011) afirma que a educação em saúde está reconhecida amplamente como uma das principais atribuições do ACS, mas que não há clareza sobre a concepção de educação em saúde que orienta suas práticas.

Os ministérios da Saúde e da Educação, como podemos identificar no Referencial curricular para curso técnico de agente comunitário de saúde, afirmam: 
Este profissional atua no Sistema Único de Saúde, no campo de interface intersetorial da assistência social, educação e meio ambiente, desenvolvendo ações de promoção da saúde e prevenção de doenças por meio de processos educativos em saúde, privilegiando o acesso às ações e serviços de informação e promoção social e de proteção e desenvolvimento da cidadania, no âmbito social e da saúde (Brasil, 2004, p. 17).

Além disso, a lei n. 10.507, que criou a profissão do ACS em 2002, estabelece a educação em saúde como instrumento para o exercício de suas atividades. Em 2006, a Política Nacional de Atenção Básica (Brasil, 2006b), que passa a reger as atividades dos ACS, apresenta a educação em saúde, coletiva e individual, no conjunto de atribuições dos ACS, o que não foi modificado pela portaria n. 2.488, de outubro de 2011, que aprova a nova Política Nacional de Atenção Básica (Brasil, 2011).

Nos diversos contextos em que o ACS se inclui, sob o rótulo de educação em saúde, ele desempenha um trabalho complexo, que se situa na confluência de saberes da saúde e do campo social. Apropriar-se de uma concepção emancipatória da educação - na sua relação com o campo da saúde - impõe dois desafios para as equipes e para os gestores da saúde: no plano ontológico, compreender a relação saúde e doença como produtos de um processo histórico e social, expressos em uma realidade concreta na qual interagem o material, o cultural e o político; e no plano político, configurar processos de trabalhos coerentes com essa compreensão.

Contrariamente à perspectiva crítico-emancipatória, confluem sobre o ACS expectativas que enfatizam sua expressão mais instrumental, em detrimento de seu potencial de criação. Tais expectativas são típicas de uma sociedade que se conforta com a divisão entre 'trabalho manual' e 'trabalho intelectual' e que sustenta, teórica e politicamente, esse modo de situar o segmento de trabalhadores de nível médio. David (2011) afirma que a vertente educativa de caráter reprodutor é predominante nos serviços de saúde, o que evidencia uma contradição em relação aos discursos produzidos pela política que incorporam os temas da transformação e da educação popular.

Cabe lembrar que, no modo de produção capitalista, como destaca Ramos (2007, p. 41), ocorreu uma “divisão entre as esferas do conhecimento e da produção; da ciência e da técnica; da teoria e da prática. (...). O trabalhador, ao invés de sujeito de conhecimento, de reflexão e imaginação, passa a ser considerado como parte das máquinas", tendo seu trabalho resumido ao desempenho de um conjunto de tarefas simples. Assim, formalmente, não se exige nem se oferece "mais conhecimentos do que aqueles estritamente necessários para realizar operações simples" (Ramos, 2007, p. 41).

David (2011) reconhece certa tendência a se perceber o ACS a partir de uma perspectiva tecnicista que integra o modelo assistencial baseado na 
racionalidade biomédica. Tal perspectiva tenderia a colocar a origem comunitária do ACS a serviço do controle que o Estado exerce sobre a população por meio das ações que realiza, disseminando, com o trabalho do ACS, vigilância e controle da ordem médica na comunidade.

A questão que permanece é identificar que elementos da política de atenção primária à saúde no Brasil, concebida como a Estratégia Saúde da Família, repercutem no trabalho do ACS, reforçando sua indefinição e situação de subalternidade na divisão social do trabalho e, em última instância, orientam suas práticas para um distanciamento de uma educação de caráter emancipatório, para ocupar o lugar de agentes atualizadores de certo campanhismo, mais diversificado, ao qual as ideias que sustentam a APS desde suas origens deveriam se contrapor.

Importa ressaltar que o ACS se insere formalmente no SUS, no contexto de alteração do modelo, o que deve implicar mudanças na formação desse trabalhador para que "realmente se deflagre um processo de reorganização da força de trabalho em saúde e contribua decisivamente para a efetivação da política nacional de saúde" (Mendonça, 2004, p. 356), que não se caracterize pela ampliação de um trabalho simplificado. Afirmamos ainda a impossibilidade de tornar perene e consistente a reorientação do modelo de atenção sem rever as formas de gestão do trabalho, oferecendo condições de fixação, remuneração, garantias e direitos aos trabalhadores do setor, sem distinção de origem ou perfil social.

\section{Considerações finais}

O recurso da análise histórica permite observar que o modelo de atenção contínua e próxima às comunidades atravessou décadas, tendo representado uma proposta contra-hegemônica que antagonizou com modelos verticalizados, centralizadores, mas que também serviu de base a modelos de desenvolvimento econômico, oferecendo a segurança sanitária aos processos de produção. As diversas configurações desse modelo sofreram a influência técnico-política de organismos e instituições no âmbito internacional, que se articulam em diversos contextos, inclusive no brasileiro.

Em sua formulação mais recente, assumiu o papel de enfoque estratégico, vetor de mudanças no modelo de atenção, incorporando a denominação de atenção primária à saúde (APS), difundida mundialmente.

Longe de haver consenso em torno desse enfoque, pode-se dizer que a APS hoje abrange projetos e interesses distintos que, de um lado, tendem a restringir os direitos sociais e a participação direta do Estado na sua provisão e, de outro, constituem-se em movimentos que buscam a ampliação desses direitos e a confirmação do dever do Estado na sua garantia. 
Na base da APS encontra-se um trabalhador, o comunnity health worker, que demonstra extrema sensibilidade às nuances que se estabelecem conforme o resultado dessas disputas, afetando diretamente a definição de seus atributos profissionais e responsabilidades, os requisitos de ingresso no trabalho, a forma de vinculação, remuneração, formação e organização do processo de trabalho.

No Brasil a atenção primária tem sido fortalecida por medidas que se articulam em diversos planos, tais como a criação de estruturas técnicas e políticas no âmbito governamental, aprovação de legislações de caráter diverso e a clara indução orçamentária que contribui para que as ações, tendo a APS como referência, sejam assumidas como prioritárias. Desse modo, podemos afirmar a existência de um cenário favorável à ampliação da atenção à saúde, de caráter público, por essa via.

Isso não nos isenta de levantar questões sobre políticas, processos e práticas que interferem diretamente na qualidade da atenção primária e no sentido do seu desenvolvimento em relação a três princípios estruturantes do SUS: a universalidade, a integralidade e a equidade.

Neste texto, as principais preocupações nos remetem à inserção do trabalhador comunitário da saúde no SUS. Esse trabalhador tem em sua trajetória os traços do trabalho voluntário e da oferta de atenção simplificada em contextos de extrema carência, mas tem também presentes elementos da mobilização e da educação popular em saúde, principalmente, nos primeiros trabalhadores recrutados para esta função.

Na Estratégia Saúde da Família, política que inseriu o ACS no SUS, prevaleceu e foi difundido um perfil social para este trabalhador construído a partir de dois elementos básicos: a identidade com a comunidade e o pendor à solidariedade.

Mesmo tendo sido reconhecida a sua profissão e indicada a sua formação técnica, o ACS continua enfrentando fortes resistências à sua profissionalização, ancoradas nesse perfil social e sustentadas por contingências orçamentárias e aparatos legais que conformam as restrições às políticas e aos direitos sociais no Brasil, como é o caso da Lei de Responsabilidade Fiscal.

Nossa argumentação é no sentido de apontar para a não dissociação entre o futuro da atenção primária à saúde no Brasil e o equacionamento de uma questão fundamental no âmbito da gestão do trabalho: a expansão do direito à saúde associada à subtração de direito dos trabalhadores do setor, particularmente do ACS.

A reorientação do modelo de atenção associou-se a um modelo de gestão do trabalho que se incompatibiliza com a possibilidade de haver trabalhadores autônomos, críticos, bem formados do ponto de vista técnico, político e ético e, assim, capazes de operar o modelo segundo as diretrizes da Estratégia Saúde da Família. 
O ACS, trabalhador da atenção básica que tem na educação em saúde o principal eixo de seu trabalho, pode vir a ser um educador popular, promotor de mudanças, provocador de participação e transformação social, mas estas são habilidades que precisam ser formadas. Sem essa qualificação, que encontra atualmente na formação em nível técnico sua expressão mais apropriada, o ACS fica mais vulnerável a assumir a reprodução de fragmentos do conhecimento instituído no âmbito das profissões em saúde de forma instrumental. Uma possível repercussão desse processo é a incorporação acrítica de práticas educativas de cunho autoritário e meramente medicalizadoras como estruturantes de sua atuação.

\section{Notas}

1 Escola Politécnica de Saúde Joaquim Venâncio, Fundação Oswaldo Cruz, Rio de Janeiro, RJ, Brasil.

Doutora em Saúde Pública pela Escola Nacional de Saúde Pública Sergio Arouca, da Fundação Oswaldo Cruz. <afonseca@fiocruz.br>

Correspondência: Fundação Oswaldo Cruz, Escola Politécnica de Saúde Joaquim Venâncio, Laboratório de Educação Profissional em Atenção à Saúde, Avenida Brasil, 4.365, Manguinhos, CEP 21040-360, Rio de Janeiro, Brasil.

2 Escola Politécnica de Saúde Joaquim Venâncio, Fundação Oswaldo Cruz, Rio de Janeiro, RJ, Brasil.

Mestre em Saúde Coletiva pelo Instituto de Medicina Social, da Universidade Estadual do Rio de Janeiro.< mguima@fiocruz.br>

3 Escola Nacional de Saúde Pública Sergio Arouca, Fundação Oswaldo Cruz, Rio de Janeiro, RJ, Brasil.

Doutora em Saúde Coletiva pela Universidade do Estado do Rio de Janeiro.

$<$ mhelenam@ensp.fiocruz.br>

4 Por ser a capital federal na época, o Rio de Janeiro era considerado um espaço de experimentação de propostas que poderiam ser expandidas no território nacional. São Paulo, por sua vez, ao concentrar poder econômico e político, era um estado no qual surgiam e se difundiam modelos de atuação em saúde. Nesses locais encontravam-se também os sanitaristas de maior renome e importância política da época.

5 No livro citado não consta o critério "residir na comunidade em que atuariam", também importante para a compreensão das limitações impostas à profissionalização dos ACS e das argumentações que foram colocadas pelos atores sociais em defesa dessa situação.

6 Em 2006 é aprovada no Brasil a emenda constitucional n. 51 que prevê a seleção pública como forma de ingresso para agentes comunitários de saúde (e agentes de endemias) e a sua contratação direta pelos estados, Distrito Federal e municípios. Entretanto, até hoje, a vinculação institucional desses trabalhadores ainda levanta controvérsias quanto à exigência ou não da contratação direta e quanto ao reconhecimento das seleções realizadas como processos públicos. 


\section{Referências}

AROUCA, Sérgio. A emergência da Medicina Preventiva. In: AROUCA, Sérgio. O dilema preventivista: contribuição para a compreensão e crítica da medicina preventiva. Rio de Janeiro: Editora Fiocruz; São Paulo: Editora Unesp, 2003. p. 109-150.

BORNSTEIN, Vera J.; STOTZ, Eduardo N. O trabalho dos agentes comunitários de saúde: entre a mediação convencedora e a transformadora. Trabalho, Educação e Saúde, Rio de Janeiro, v. 10, n. 2, p. 457-480, 2008.

BRASIL. Ministério da Saúde. Conferência Nacional de Saúde, 8., Brasília, 1986. Relatório final. Brasília: Ministério da Saúde, 1986a.

Ministério da Saúde. Conferência Nacional de Recursos Humanos para a Saúde, 1., 1986, Brasília. Relatório final. Brasília: Ministério da Saúde, 1986b.

- Ministério da Saúde. Portaria n. 1.886 de 18 de dezembro de 1997. Aprova as Normas de Diretrizes do Programa de Agentes Comunitários de Saúde e do Programa de Saúde da Família. Disponível em: $<$ www.brasilsus.com.br/legislacoes/gm/ 13421-1886.html>. Acesso em: 3 jun. 2012.

Ministério da Saúde. Ministério da Educação. Referencial curricular para o Curso Técnico de Agente Comunitário de Saúde: área profissional saúde. Brasília, MS, 2004. (Série A. Normas e Manuais Técnicos). Disponível em: <http://bvsms.saude.gov.br/ bvs/publicacoes/referencial_curricular_ acs2.pdf>. Acesso em: 1 jul. 2012.

Lei n. 10.507, de 10 de julho de 2002. Cria a profissão de Agentes Comunitários de Saúde e dá outras providências. Brasília, 2002. Disponível em: <www010.dataprev. gov.br/sislex/paginas/42/2002/10507.htm>. Acesso em: 10 jul. 2012

Ministério da Saúde. Portaria GM/MS n. 648 , de 28 de março de 2006. Aprova a Política Nacional de Atenção Básica, esta- belecendo a revisão de diretrizes e normas para a organização da Atenção Básica para o Programa Saúde da Família (PSF) e o Programa de Agentes Comunitários de Saúde (Pacs). Brasília, 2006a. Disponível em: <http:// dtr2001.saude.gov.br/sas/PORTARIAS/ Port2006/GM/GM-648.htm>. Acesso em: 9 jul. 2012.

Lei n. 11.350, de 5 de outubro de 2006. Regulamenta o § 5o do art. 198 da Constituição, dispõe sobre o aproveitamento de pessoal amparado pelo parágrafo único do art. $2^{\circ}$ da Emenda Constitucional no 51, de 14 de fevereiro de 2006, e dá outras providências. Brasília, 2006b. Disponível em: <www.planalto.gov.br/ccivil_03/_ato20042006/2006/lei/111350.htm>. Acesso em: 16 jul. 2012.

Ministério da Saúde. Portaria n. 2.488, de 21 de outubro de 2011. Aprova a Política Nacional de Atenção Básica, estabelecendo a revisão de diretrizes e normas para a organização da Atenção Básica, para a Estratégia Saúde da Família (ESF) e o Programa de Agentes Comunitários de Saúde (PACS). Brasília, 2011. Disponível em: <www.brasilsus.com.br/legislacoes/gm/ 110154-2488.html>. Acesso em: 16 jul. 2012.

CAMPOS, CARLOS E. A. 1999. Centros Municipais de Saúde do Rio de Janeiro: reconstrução da trajetória de uma organização sanitária. 1927-1997. 1999. Tese (Doutorado em Medicina Preventiva), Departamento de Medicina Preventiva, Faculdade de Medicina, Universidade de São Paulo, 1999.

CAMPOS, André L. V. Politicas internacionais de saúde na era Vargas: o serviço especial de saúde pública 1942-1960. Rio de Janeiro: Editora Fiocruz, 2006.

CASTRO SANTOS, Luiz A.; FARIA, Lina. Os primeiros centros de saúde nos Estados Unidos e no Brasil: um estudo comparativo. Teoria e Pesquisa, São Carlos, n. 40, p. $137-$ 182, jan./jul. 2002. 
CONILL, Eleonor M. Ensaio histórico-conceitual sobre a Atenção Primária à Saúde: desafios para a organização de serviços básicos e da Estratégia Saúde da Família em centros urbanos no Brasil. Cadernos de Saúde Pública, Rio de Janeiro, v. 24, sup.1, p. S7-S27, 2008.

CUETO, Marcos. The origins of primary health care and selective primary health care. American Journal of Public Health, New York, v. 94, n. 11, p. 1864-74, 2004.

DAVID, Helena M. S. L. Educação em saúde e o trabalho dos agentes comunitários de saúde. In: MIALHE, Fabio L. (Org.). O agente comunitário de saúde: práticas educativas. Campinas: Editora Unicamp, 2011. p. 41-50.

DONNANGELO, Maria C.; PEREIRA, Luiz. Medicina comunitária: politica médica, politica social. In: DONNANGELO, Maria C.; PEREIRA, Luiz. Saúde e sociedade. São Paulo: Duas Cidades, 1976. p. 75-94.

DURÃO, Anna V.; MOROSINI, Márcia V.; CARVALHO, Valéria. Os agentes comunitários de saúde e o conceito de comunidade. In: VIEIRA, Monica; DURÃO, Anna V.; LOPES, Marcia R. (Org.) Para além da comunidade: trabalho e qualificação dos agentes comunitários de saúde. Rio de Janeiro: EPSJV, 2011. p. 119-160.

FARIA, Lina. A casa de Geraldo de Paula Souza: texto e imagem sobre um sanitarista paulista. História Ciência e Saúde: Manguinhos, Rio de Janeiro, v. 12, n. 3, p. 1011-1024, 2005.

Educadoras sanitárias e enfermeiras de saúde Pública: identidades profissionais em construção. Cadernos Pagu, 2006, São Paulo, n. 27, p. 173-212, jul./dez. 2006.

FARIA, Lina; COSTA, Maria C. Cooperação científica internacional: estilos de atuação da Fundação Rockefeller e da Fundação Ford. Dados, Rio de Janeiro, v. 49, n. 1, p. 159191, 2006.

FAUSTO, Marcia C. R.; MATTA, Gustavo C. Atenção primária à saúde: histórico e pers- pectivas. In: MOROSINI. Marcia V.; CORBO, Anamaria. (Org.). Modelos de atenção e a saúde da família. Rio de Janeiro: EPSJV; Editora Fiocruz, 2007. p. 43-67. (Coleção Educação Profissional e Docência em Saúde: a Formação e o Trabalho do Agente Comunitário de Saúde).

FONSECA, Angélica F.; MACHADO, Filipe R.; BORNSTEIN, Vera J. et al. Avaliação em saúde e repercussões no trabalho do agente comunitário de saúde. Texto Contexto Enfermagem, Florianópolis, v. 21, n. 3, p. 519527, jul./set. 2012.

GIOVANELLA, Ligia. Atenção primária à saúde seletiva ou abrangente?. Cadernos de Saúde Pública, Rio de Janeiro, v. 24, sup. 1, p. s21-s23, 2008.

HEAVER, Richard. Managing Primary Health Care: Implications of the Health Transitions. Washington DC: World Bank, 1995. 41p. (World Bank discussion paper).

DUFFY, John. The new public health. In: DUFFY, John. The Sanitarians: a History of American Public Health. Urbana: University of Illinois Press, 1990. p. 205-220.

MELLO, Guilherme A.; FONTANELLA, Bruno J. B.; DEMARZO, Marcelo M. P. 2009. Atenção básica e atenção primária à saúde: origens e diferenças conceituais. Revista de APS, Juiz de Fora, v. 12, n. 2, p. 204-213, abr./ jun. 2009.

MENDONÇA, Maria H. M. Profissionalização e regulação da atividade do ACS no contexto da Reforma Sanitária. Trabalho, Educação e Saúde, Rio de Janeiro, v. 2 n. 2, p. 353-365, 2004.

NITERÓI. Prefeitura Municipal. Secretaria Municipal de Saúde. Fundação Municipal de Saúde. In. CONFERÊNCIA NACIONAL DE SAUDE, 3. Anais... Niterói: Prefeitura Municipal de Niterói, 1992. Disponível em: <http:// portal.saude.gov.br/portal/arquivos/pdf/3 CNS_anais.pdf $>$. Acesso em: 15 jul. 2012.

MERHY, Emerson E. A saúde pública como política: São Paulo, 1920-1948, os movimentos 
sanitários, os modelos tecno-assistenciais e a formação das políticas governamentais. São Paulo: Hucitec, 1992.

MOROSINI, Márcia V. G. C. Educação e trabalho em disputa no SUS: a política de formação dos agentes comunitários de saúde. Rio de Janeiro: EPSJV, 2010.

OGUISSO, Taka; CAMPOS, Paulo F. S.; SANTIAGO, Emiliane S. Maria Rosa Pinheiro e a reconfiguração da enfermagem brasileira. Texto Contexto Enfermagem, Santa Catarina, v. 18, n. 4, p. 643-651, 2009.

ORGANIZAÇÃO MUNDIAL DE SAÚDE. UNICEF. 1979. Declaração de Alma-Ata. Conferência Internacional sobre Cuidados Primários de Saúde. Relatório. Alma-Ata, URSS, 6 a 12 de setembro de 1978. Brasil: Unicef, 1979.

ORGANIZAÇÃO PAN-AMERICANA DESAÚDE (OPAS). Renovação da atenção primária nas Américas: documento de posicionamento da Organização Pan-americana de Saúde. Washington: Opas, 2005.

RAMOS, Marise N. Conceitos básicos sobre trabalho. In: FONSECA, Angélica; Stauffer, Anakeila (Org.). O processo histórico do trabalho em saúde. Coleção Educação Profissional e Docência em Saúde: a formação e o trabalho do Agente Comunitário de Saúde. Rio de Janeiro: EPSJV/Editora Fiocruz, v. 5, 2007. p. 27-56.

RENOVATO, Rogério D.; BAGNATO, Maria Helena S. Educação sanitária e o Serviço Especial de Saúde Pública (1942-1960): a doença não conhece fronteiras. História da Enfermagem: Revista Eletrônica, Brasília, v. 2, p. 105-125, 2011.

RIBEIRO, Fátima A. Atenção primária (APS) e sistema de saúde no Brasil: uma perspectiva histórica. 2007. Dissertação. (Mestrado Preventiva) - Faculdade de Medicina da Universidade de São Paulo, Departamento de Medicina Preventiva, 2007.

RIZZOTO, Maria L. F. O Banco Mundial e as políticas de saúde no Brasil nos anos 90: um projeto de desmonte do SUS. 2000. Tese (Doutorado em Saúde Coletiva) - Campinas: Faculdade de Ciências Médicas, Universidade Estadual de Campinas, 2000.

SÃO PAULO (Estado). Decreto n. 4.089, de 17 de agosto de 1926. Manda observar o regulamento do Curso de Educadores Sanitários. Disponível em: <www.al.sp.gov.br/ repositorio/legislacao/decreto/1926/decreto n.4.089/17.08.1926.htm>. Acesso: 1 ago. 2012.

SILVA, Joana A.; DALMASO, Ana S. W. O Agente comunitário de saúde e suas atribuições: os desafios para os processos de formação de recursos humanos em saúde. Interface: Comunicação, Saúde e Educação, Botucatu, v. 6, n. 10, p. 75-83, fev. 2002.

TEIXEIRA, Carla C. Interrompendo rotas, higienizando pessoas: técnicas sanitárias $\mathrm{e}$ seres humanos na ação de guardas e visitadoras sanitárias. Ciência \& Saúde Coletiva, Rio de Janeiro, n. 3, v. 13, p. 965-974, 2008.

THE WORLD BANK. Health: Sector Policy Paper. Washington, D.C.: The World Bank, 1975.

Financing health services in developing countries: an agenda for reform. Washington: World Bank, 1987. Disponível em: <www-wds.worldbank.org/external/ default/WDSContentServer/WDSP/IB/1999/ 09/23/000178830_98101903343495/Rendered/ PDF/multi_page.pdf>. Acesso em: 13 jul. 2012.

VIANA, Ana L. D.; DAL POZ, Mario R. A reforma do sistema de saúde no Brasil e o Programa de Saúde da Família. Physis: Revista de Saúde Coletiva, Rio de Janeiro, v. 15, sup., p. 225-264, 2005.

WALT, Gill. Community Health Workers in National Programme: Just Another Pair of Hands? Philadelphia: Open University Press, 1990.

WORLD HEALTH ORGANIZATION (WHO). Alternative Approaches to Meeting Basic Health Needs of Populationsin Developing Countries. Geneva: World Health Organization, 1975. 
(WHO). Primary Health Care: Now More Than Ever. Geneva: WHO, 2008. (The World Health Report 2008).

(WHO). Strengthening Health services. In: WORLD HEALTH ORGANIZATION (WHO). The Third Ten Years of WHO: 1968-1977. Gevene: WHO, 2008. p. 117-131.
(WHO). Strengthening the Performance of Community Health Workers in Primary Health Care: Report of a WHO Study Group. Geneva: WHO, 1989. (World Health Organization. Technical Report Series, n. 780). Disponível em: <http://whqlibdoc. who.int/trs/WHO_TRS_780.pdf > Acesso: 1 ago. 2012.

Recebido em 01/10/2012

Aprovado em 23/11/2012 